\title{
Prevalence and Causes of Self Medication among Medical Students of Kerman University of Medical Sciences, Kerman, Iran
}

\author{
Marziyeh Zardosht ${ }^{1}$, Maryam Dastoorpoor ${ }^{2}$, Farzaneh Bani Hashemi ${ }^{3}$, Fatemeh Estebsari ${ }^{4}$, \\ Ensiyeh Jamshidi ${ }^{5}$, Abbas Abbasi-Ghahramanloo ${ }^{6}$ \& Payam Khazaeli $^{7}$ \\ ${ }^{1}$ School of Management and Information, Kerman University of Medical Sciences, Kerman, Iran \\ ${ }^{2}$ Modeling in Health Research Center, Institute for Futures Studies in Health, Kerman University of Medical \\ Sciences, Kerman, Iran \\ ${ }^{3}$ Hormozgan University of Medical Sciences, Bandar Abbas, Iran \\ ${ }^{4}$ Department of Health, School of Nursing and Midwifery, Shahid Beheshti University of Medical Sciences, \\ Tehran, Iran \\ ${ }^{5}$ Community Based Participatory Research Center, Iranian Institute for Reduction of High-Risk Behaviors, \\ Tehran University of Medical Sciences, Tehran, Iran \\ ${ }^{6}$ Department of Epidemiology, Iran University of Medical Science, Tehran, Iran \\ ${ }^{7}$ School of Pharmacy and Pharmaceutical Research Center, Kerman University of Medical Sciences, Kerman \\ Correspondence: Fatemeh Estebsari, Department of Health, School of Nursing and Midwifery, Shahid \\ Beheshti University of Medical Sciences, Vali Asr Ave, Niayesh Cross Road, Niayesh Complex, Tehran \\ 1985717443, Iran. Tel: 98-21-8865-5366. E-mail: fa_estebsari@yahoo.com
}

Received: October 302015 Accepted: March 7, 2016 Online Published: March 23, 2016

doi:10.5539/gjhs.v8n11p150 URL: http://dx.doi.org/10.5539/gjhs.v8n11p150

\begin{abstract}
Background: Self-medication is a public health concern because of drug misuse/abuse and its medical, social and psychological problems.
\end{abstract}

Aim: Given the growing prevalence of self-medication, the present study aims to determine the prevalence and causes of self-medication among students of Kerman University of Medical Sciences.

Method: This cross-sectional study was conducted in 2014 on 550 students who were selected through multistage sampling from Kerman University of Medical Sciences, Kerman, in southeast Iran. Data was collected through a self-report questionnaire. Test-retest reliability and content validity of this questionnaire were confirmed. Data analysis was carried out using descriptive and inferential statistics via t-test and analysis of variance (ANOVA).

Results: The prevalence of self-medication among students was $50.2 \%$. The most common cause of self-medication was related to students' knowledge about the diseases and medications (58.7\%). The majority of drugs consumed arbitrarily included cough and cold medications (94.5\%); analgesics (89.9\%); antihistamines $(80.0 \%)$; herbal drugs and distillates $(78.9 \%)$; vitamins, minerals, dietary supplements and energizers $(71.5 \%)$; antibiotics (61.8\%); and gastrointestinal drugs (54.9\%), respectively. The most common illness that led to self-medication was the common cold (95.4\%), and the most important source of information regarding self-medication was the students' own scientific knowledge of medical drugs $(80.6 \%)$.

Conclusion: Due to the adverse effects of self-medication, drug dependency, and microbial resistance and the relatively high prevalence of self-medication among students in this study, it would be advisable to organize awareness campaigns to further educate students about self-medication.

Keywords: prevalence, self-medication, drug therapy, students

\section{Introduction}

Drugs are chemical substances used or intended for use in the treatment, prevention, or diagnosis of disease (Shamsi \& Bayati, 2010). Self-medication occurs when individuals use drugs without a prescription, recommendation or control of a licensed healthcare specialist (Albarrán \& Zapata, 2008). 
In self-medication, an individual, caretaker(s) or guardian(s) responsible for the individual, decide, without any medical evaluation, which drug to use and how to take that drug for a specific condition. Self-medication includes sharing prescribed medications with friends and family members who did not have that drug prescribed to them, using remaining drugs from previous prescriptions, or non-compliance with the prescribed medication by extending the duration of its usage or interrupting the dosage (Pfaffenbach, Tourinho, \& Bucaretchi, 2010).

Studies show that the lack of sufficient time to visit a physician, believing in the safety of drugs, collecting and storing old medications at home, easy access to drugs, and the selling of drugs without a prescription are some of the factors affecting self-medication (Alghanim, 2011; Amani, Mohammadi, Shaker, \& Shahbazzadegan, 2011). Medical complications resulting from self-medication include: bacterial resistance, hidden signs and symptoms of the underlying disease, delay in diagnosis, incomplete treatment, drug dependency, drug interactions, unintentional poisoning, liver and renal disorders, and reduced quality of life (Amani et al., 2011; Ansari, Abshenas, Khanzadeh, \& Masoudi, 2007; Mumtaz, Jahangeer, Mujtaba, Zafar, \& Adnan, 2011; Sawalha, 2007).

Based on the estimation of The World Health Organization, pharmaceutical costs account for almost $40 \%$ of all therapeutic expenses (Yousefi, Majdzadeh, Valadkhani, Nedjat, \& Mohammadi, 2012). Self-medication as a result of the improper use of medicine is a major problem around the world. In this regard, the World Health Organization estimates that more than half of all medicines are inappropriately prescribed, dispensed or sold, while $50 \%$ of all patients take the medicine prescribed for them incorrectly (World Health Organization, 2002).

Today, the excessive improper use of drugs is one of the most critical social, economic and health challenges of countries around the world, including Iran. Studies show that about $83.3 \%$ of Iranians self-medicate with drugs and $35 \%$ of all medicines are taken without a prescription (Masoudi Alavi, Izadi, Ebadi, \& Hajbagheri, 2009). Self-medication is prevalent among different population groups, and its rate varies across different regions (Almasdy \& Sharrif, 2011). The prevalence of self-medication among Palestinian, Slovenian, and Pakistani students was reported to be about 98\%, 92.3\%, and 80.4\%, respectively (Sawalha, 2007). Likewise, self-medication has a high prevalence among Iranian students; the rate of self-medication among students at the University of Ardabil and Shahid Sadoughi University of Medical Sciences of Yazd has been reported to be more than 83\% (Amani et al., 2011; Baghianimoghadam \& Ehrampoush, 2006). Self-medication among students, especially medical students, is an important issue that can, in many cases, cause serious consequences. It is incorrect to assume that medical students are less prone to self-medication because of their knowledge of pharmacological drugs. On the contrary, this knowledge contributes to an increase of self-medication (da Silva, Soares, \& Muccillo-Baisch, 2012). Furthermore, the use of social media among medical students can have a crucial effect on self-medication. These communications play a key role in providing these students with assistance, advice, and information about medicines and their use.

This study was conducted to determine the prevalence and causes of self-medication among students in Kerman University of Medical Sciences in 2014.

\section{Method}

\subsection{Study Population and Sampling}

This is a cross sectional, 8-month study carried out in 2014 among students of Kerman University of Medical Sciences of Kerman located in the city of Kerman in southeast Iran. Given the lack of accurate information about the prevalence of self-medication among students in Iran, the required sample size was estimated to be 600 individuals considering a prevalence rate of $50 \%$, the confidence interval of $95 \%$, and the percision of 0.04 using the following formula:

$$
\mathrm{n}=\frac{Z_{1-\frac{\alpha}{2}}^{2} \times p \times(1-p)}{d^{2}}
$$

In this study, 71 participants did not fill out the questionnaire (response rate: $88.2 \%$ ); therefore, the data of 529 questionnaires was included in a database for statistical analysis.

The sampling process began after the Medical Ethics Committee of Kerman University of Medical Science approved the research proposal and provided permission to carry out the study. The students were selected by the stratified sampling method. To determine the sample size in each strata, the probability-proportional-to-size method was used. The students were classified into three strata. Sample size was determined based on the population of each strata. Each strata was determined by students' types of degrees. The strata included were: medical sciences (medicine, dentistry, and pharmacology) $(\mathrm{n}=469)$; health sciences (health education, public health, family health, maternal and child health and reproductive health) $(\mathrm{n}=36)$; and paramedical sciences 
(nursing, midwifery, health management, and health economics) $(\mathrm{n}=95)$.

The sample size in each strata was determined by the students' educational degree, number of classrooms and the proportion of students per class. In each classroom, samples were selected by using a table of random numbers. The questionnare was completed by the selected samples.

\subsection{Data Gathering}

The data collection questionnaire included two sections on demographic information and self-medication:

1). Demographic information included age, sex (male, female), marital status (single, married), residential place (Kerman city, Kerman Province, outside the Kerman Province), current location of residence in Kerman (family home, dorm, etc.), field of study, level of education (AS, BS, MS, DVM, PhD and above), employment status (employed, unemployed), and basic and supplementary health insurance coverage status. Other demographic questions were: Where did you spend most of your life? (City, Village); as a student, how difficult is it to cover the cost of attendance at the university? (1- I'm able to cover it without any concern; 2- It is difficult to a moderate extent; 3 - It is extremely difficult; 3 - It is extremely difficult and most of my living expenses are met by working).

2). Questions related to self-medication: This section includes 82 questions on a Likert scale and two-choice answers. Questions of self-medication questionnaire were based on following items:

1. Practicing self-medication in the time of illness or pain (7 questions assessed with the Likert Scale: Always, Most of the time, Sometimes, Rarely, Never); 2. The effects of various factors on the self-medication (16 questions assessed with the Likert Scale: Very high, High, Moderate, Low, Very low); 3. Preventive factors of self-medication (7 questions assessed with the Likert Scale: Very high, High, Moderate, Low, Very low); 4. Sources of information (14 questions two answer choices: Yes or No); 5. Types of medications that are used arbitrarily (13 questions two answer choices: Yes or No); 6. Illnesses that lead to self-medication (16 questions two answer choices: Yes or No); 7. Sources of drug supply (8 questions two answer choices: Yes or No); and 8. Kinds of self-medication in cases such as the cold, an unusual disease or other symptoms (such as a headache more severe than an ordinary headache), (1 question assessed with the Likert Scale: "I have never self-medicated," or "I always self-medicate.").

Content validity of the questionnaire was confirmed by the judgment of a panel of 10 faculty members in Kerman University of Medical Sciences. The reliability of this tool was assessed using the test-retest method. The questionnaire was administered on 10 eligible participants twice with a two-week interval in between the completion of each questionnaire. The correlation coefficient was obtained as equal to 0.95 .

Data was collected through interviews by a trained interviewer. Before completing the questionnaire, the objectives of the study were explained in detail to each participant, and the questionnaire was completed after obtaining informed consent.

\subsection{Data Analysis}

The data was collected and analyzed using SPSS software, version 20. To analyze the data, descriptive statistics indicators such as frequency, percentage, mean and standard deviation were applied; and to test the research hypotheses, the independent t-test and ANOVA with 95\% confidence interval and 0.05 significance level were used.

\subsection{Ethics}

The protocol of this study was approved by ethics committee of Kerman University of Medical Sciences (Code No: 91/345, Date: January 15, 2013). The anonymity of participants was assured and maintained. Informed consent was obtained from participants prior to study.

\section{Results}

The average age of males and females participating in the study was $22.9 \pm 2.3$ and $22.5 \pm 2.5$, respectively. In this study, 377 of participants (71.3\%) were female, 444 (83.9\%) were single, 485 (91.7\%) were unemployed and $359(67.9 \%)$ were residing in a dormitory. Regarding participants' education, 181 participants $(34.2 \%)$ were undergraduate students, $46(8.7 \%)$ were graduate students and $302(57.1 \%)$ were $\mathrm{PhD}$ students. The location of residence of the families of 132 participants was in Kerman city (25\%), 186 in Kerman province (35.2\%), and 211 outside of the Kerman province (39.8\%). In total, 488 of 529 participants $(92.2 \%)$ had spent most of their lives in the city, and the rest spent most of their lives in rural areas.

Of all participants, $331(62.2 \%)$ expressed that they had no concern about how to afford the cost of attendance 
while studying at the university. Results showed that 476 (90\%) of participants were covered by the basic insurance, and of those students, $156(32.8 \%)$ were under supplemental insurance coverage. On average, 50.2\% of participants in the study practiced self-medication.

In this study, the most common health problems for which participants in the study practiced self-medication were: the common cold $(95.4 \%)$, headache $(82 \%)$, allergy (73.4\%), insufficient vitamins and minerals $(70.2 \%)$, respiratory disease $(67.7 \%)$, and gastrointestinal problems $(62 \%)$.

The types of drugs consumed arbitrarily included cold and cough medications (94.5\%); analgesics (89.9\%); antihistamines $(80.0 \%)$; herbal drugs and distillates (78.9\%); vitamins, minerals, dietary supplements and energizers (71.5\%); and antibiotics (61.8\%), respectively (Table 1).

Table 1. Frequency of nonprescription drugs consumption among participants

\begin{tabular}{lll}
\hline Type of drugs & $\mathbf{N}$ & $\mathbf{\%}$ \\
\hline Antibiotics & 327 & 61.8 \\
Cold and cough medicines & 500 & 94.5 \\
Analgesics & 476 & 89.9 \\
Gastrointestinal drugs & 290 & 54.9 \\
Drugs for treatment of hair and skin disorders & 168 & 31.7 \\
Cardiovascular drugs & 56 & 10.5 \\
Antihistamines & 423 & 80.0 \\
Antidepressants and Antianxiety & 154 & 29.1 \\
Stimulants & 41 & 7.8 \\
psychotropic drugs & 27 & 5.1 \\
Others & 0 & 0 \\
\hline
\end{tabular}

The majority of students reported that the drugs they used for self-medication came from pharmacies (89.4\%). Nearly $75 \%$ of students surveyed were taking drugs leftover from previous prescriptions at the home or dormitory (Table 2).

Table 2. Frequency of nonprescription drug suppliers among participants

\begin{tabular}{lll}
\hline Suppliers & N & $\mathbf{\%}$ \\
\hline Drugs left over from previous prescriptions in the home or dormitory & 394 & 74.5 \\
Drugs left over that were not previously prescribed & 115 & 29.3 \\
Buying without a prescription while already self-medicating (pharmacies) & 473 & 89.4 \\
Family, friends, relatives & 280 & 52.9 \\
Others & 0 & 0 \\
\hline
\end{tabular}

Preventive factors for self-medication among students included advice from professors, family members and acquaintances about the possibility of side effects $(45.1 \%)$, and the participants' individual knowledge about medicines $(44.7 \%)$. These two preventive factors were the two most common cited by student participants in the study (Table 3). 
Table 3. Frequency of preventive factors of self-medication among participants

\begin{tabular}{|c|c|c|c|c|c|}
\hline $\begin{array}{l}\text { Distribution of attitude scores of the preventive } \\
\text { factors affecting self-medication }\end{array}$ & Very high & High & Moderate & Low & Very low \\
\hline Fear of complications due to self-medication & 10.1 & 24.1 & 34.5 & 20.7 & 10.6 \\
\hline $\begin{array}{l}\text { Advices from the professors, family members, } \\
\text { friends and others about the possibility of } \\
\text { complications }\end{array}$ & 11.8 & 33.3 & 34.0 & 13.7 & 7.4 \\
\hline $\begin{array}{l}\text { Recommendation of television and radio } \\
\text { programs, Internet, magazines and related media } \\
\text { about the potential complications of drugs }\end{array}$ & 10.1 & 24.1 & 34.5 & 20.7 & 10.6 \\
\hline $\begin{array}{l}\text { Continuous access to a physician during training } \\
\text { and internships }\end{array}$ & 14.4 & 28.8 & 28.8 & 19.0 & 8.9 \\
\hline Student discounts at university hospitals & 12.3 & 20.7 & 28.7 & 21.8 & 16.5 \\
\hline $\begin{array}{l}\text { Coverage of basic health or supplemental health } \\
\text { insurance }\end{array}$ & 15.4 & 23.0 & 30.0 & 18.6 & 13.1 \\
\hline Scientific information in the field of medicine & 15.9 & 28.8 & 33.4 & 14.4 & 7.4 \\
\hline
\end{tabular}

Regarding drug-related sources of information, $80.6 \%$ of the participants have obtained their pharmaceutical information from personal studies, $79.5 \%$ from their professors, and $74.4 \%$ from books and published resources. Results revealed that the factors related to the participant's awareness of their disease and its medications (including self-diagnosis, experience with specific diseases and acquired knowledge of medicines to treat them, previous experience of favorable results by self-medication, and not considering disease as important for the perception of severity) had the greatest impact on self-medication among students (Table 4).

Table 4. The effects of different factors on self-medication among participants

\begin{tabular}{|c|c|c|c|}
\hline \multirow{2}{*}{ Main domains } & \multirow{2}{*}{ Sub-domains } & \multicolumn{2}{|c|}{ effects of factors } \\
\hline & & Mean & $\mathrm{SD}$ \\
\hline \multirow{5}{*}{ Having access to Health Services } & Expensive cost of physicians' visits & \multirow{5}{*}{42.8} & \multirow{5}{*}{19.6} \\
\hline & Lack of access to a physician in the emergency cases & & \\
\hline & Not having enough time to visit the physician & & \\
\hline & Limited trust to the practice of physician & & \\
\hline & Lack of insurance & & \\
\hline \multirow[b]{2}{*}{$\begin{array}{l}\text { Awareness of the disease and } \\
\text { treatment }\end{array}$} & Self-diagnosis of disease and awareness of how to treat it & \multirow{3}{*}{58.7} & \multirow{3}{*}{21} \\
\hline & $\begin{array}{l}\text { Experience of a special disease and knowledge of how to treat it } \\
\text { previous experience of favorable results by self-treatments }\end{array}$ & & \\
\hline \multirow{5}{*}{$\begin{array}{l}\text { Having access to medications and } \\
\text { Information about them }\end{array}$} & perception of severity, not considering disease as important & & \\
\hline & The availability of drugs & \multirow{4}{*}{50.4} & \multirow{4}{*}{19.3} \\
\hline & The safety of medicines & & \\
\hline & Insufficient information about the side effects of drugs & & \\
\hline & Scientific information in the field of medicine and medications & & \\
\hline \multirow{2}{*}{$\begin{array}{l}\text { Influence from } \\
\text { acquaintances }\end{array}$} & Pressures of friends and acquaintances & \multirow{2}{*}{34.6} & \multirow{2}{*}{26.3} \\
\hline & Advices from friends and acquaintances & & \\
\hline
\end{tabular}

A bivariate analysis of the results showed that no significant association was found among self-medication and demographic characteristics of participants, such as sex, marital status, insurance status, employment, affording 
the living costs, current residential location, permanent residential location and education level.

\section{Discussion}

Physicians and medical students are expected to seek appropriate medical help for problematic health situations to avoid self-prescription and self-medication (Montgomery, Bradley, Rochfort, \& Panagopoulou, 2011). The prevalence of self-medication in the present study was found to be $50.2 \%$. In studies conducted at the Bojnurd University (Ghafouri M, Yaghubi M , Lashkardoost H, \& Seyed Sharifi SH, 2013), among medical students of Tehran University of Medical Sciences (Purreza, Khalafi, Ghiasi, Mojahed, \& Nurmohammadi, 2013) and at the Arabian Gulf University of Bahrain (James, Handu, Al Khaja, Otoom, \& Sequeira, 2006), 41.9\%, 35.7\% and $44.8 \%$ of the students practiced self-medication, respectively. These results are similar to the results of the present study. However, the prevalence of self-medication among medical students was reported as higher in the other studies carried out among medical and non-medical students of the Federal University of Rio Grande in Brazil (da Silva et al., 2012), Universities of Karachi in Pakistan (Mumtaz et al., 2011), University of Ljubljana in Slovenia (Klemenc-Ketis, Hladnik, \& Kersnik, 2010), and Birjand and Ardebil universities in Iran (Amani et al., 2011; Tabiei, Farajzadeh, \& Eizadpanah, 2012) and were reported to be $86.4 \%, 80.4 \%, 92.3 \%, 86.7 \%$ and $83 \%$, respectively.

In a study by Hem et.al, which was conducted on a sample of 402 Norwegian medical interns, $54 \%$ of participants in their fourth and ninth years of postgraduate study reported to having had self-prescribed medication and self-medicated at least once during the previous year (Hem et al., 2005).

Results of a study by Brimstone et. al, showed Australian medical students self-medicated for $45 \%$ of physical problems and 56\% of mental problems (Brimstone, Thistlethwaite, \& Quirk, 2007).

A review study by Montgomery et. al, on self-medication among physicians and medical students, found that that in 76 percent of these studies, self-medication was reported at more than $50 \%$. Physicians and medical students considered self-medication to be an acceptable solution for acute and chronic conditions. In fact, informal care paths were found to be common in the medical profession (Montgomery et al., 2011).

The relatively high prevalence of self-medication among medical students can increase the side effects, risks and drug interactions, which can lead to negative attitudes towards proper drug use (Zafar et al., 2008).

In this study, the most common health problems that led to self-medication consisted of cold and common pains including headache, respiratory disease and gastrointestinal problems. Results of the current study in terms of practicing self-medication for cold and common pains corroborate those of Zufar in Karachi of Pakistan (Zafar et al., 2008), Sawalha in Palestine (Sawalha, 2007), and Siam in Rasht city of Iran (Siam SH, 2004).

Given that cold and pains are mostly treated by over-the-counter (OTC) medicines, the prevalence of self-medication for respiratory disease and gastrointestinal problems is alarming and requires more attention.

In this study, the most common therapeutic group of drugs practiced as self-medication were cold and cough medicines, analgesics, antihistamines and antibiotics, which could be due to the symptomatic treatment of the diseases and the fact that these drugs are easily accessible because they are sold as OTC drugs in pharmacies. Consistent with our results, studies of Barros et al. in Rio de Janeiro of Brazil and Verma et al. in North India showed that analgesics and cold medicines are used more than other drugs as self-medication (Barros, Griep, \& Rotenberg, 2009; Verma, Mohan, \& Pandey, 2010).

In another study by Narelle and Shadbolt on Australian junior medical officers, results showed that participants used many types of drugs arbitrarily: antibiotics (81\%), sleeping pills (38\%), antihypertensive (15\%), narcotic analgesics (7\%) and antidepressants drugs (7\%) (Shadbolt, 2002).

However, the most important finding of the current study is the use of non-OTC medicines like antibiotics and gastrointestinal drugs which are used without a prescription and can result in serious side effects like antibiotic resistance.

In this study, the pharmacy was reported as the greatest source of drug supply for self-medication. Results are consistent with those of conducted on students at Birjand University (Tabiei et al., 2012) and medical students of Tehran University of Medical Sciences (Purreza et al., 2013).

In the studies conducted in Yazd (Baghianimoghadam \& Ehrampoush, 2006), Isfahan (Eslami, Moazemi Goudarzi, Najimi, \& Sharifirad, 2012), Ardebil (Amani et al., 2011), Tehran (Purreza et al., 2013), and Bojnoord (Ghafouri et al., 2013) in Iran and Northern India (25), students reported that the reason for their self-medication was the selling of medicine by pharmacies without prescription. These findings confirm the crucial role of pharmacies in the prevalence of self-medication. 
Hooper et.al, carried out a study on UK students of medical sciences, and the results showed that $13 \%$ of fourth-year medical students had received a prescription from a friend. Students believed that that it was appropriate for physicians to self-investigate (52\%), self-refer $(59.1 \%)$ and self-prescribe $(39.2 \%)$ (Hooper, Meakin, \& Jones, 2005).

In a study by Roberts et.al which was conducted on US medical students, result showed that $22 \%$ of students requested prescriptions from other students and 34\% get help from a colleague for prescribed medication (Roberts, Hardee, Franchini, Stidley, \& Siegler, 1996).

Christie et.al, conducted a study on US resident physicians, 52\% of students reported self-prescribing medications, and $42 \%$ of self prescribed medicines were obtained from a sample cabinet and $11 \%$ from a pharmaceutical company representative (Christie et al., 1998).

According to the results, the most preventive factors for self-medication were 1) advice from professors, family members, media and magazines, and acquaintances about the possibility of complications, and 2) participants' knowledge of the field of medicine. However, in the study conducted by Eslami et al., the lack of belief in self-medication was reported as the most effective preventive factor (Eslami et al., 2012). Results demonstrated that students' own personal scientific knowledge, their professors, books and published resources were the most important sources of information regarding self-medication. However, in the studies of Eslami et al. in Isfahan, Iran, and Patricia et al., in Hartford, Connecticut, physicians as well as published resources were the most important reported sources of medical information of students about medicines (Eslami et al., 2012; Neafsey, Jarrín, Luciano, \& Coffman, 2007).

The most influential factors for practicing self-medication in this study were: 1) the awareness of individuals of their disease and its medications and, 2) previous experience with favorable results of self-medication which are consistent with the results of other studies that also pointed to these factors and others, such as time saved (by not visiting a doctor) and cost-effectiveness (Amani et al., 2011; Baghianimoghadam \& Ehrampoush, 2006; Sharifirad et al., 2012; Zafar et al., 2008). The results of the study in terms of the perception of severity of the diseases and not deeming the diseases as important are also in line with those of Baghiani Moghadam in Yazd (Baghianimoghadam \& Ehrampoush, 2006), Amani in Ardabil (Amani et al., 2011) and Shamsi in Arak of Iran (Shamsi \& Bayati, 2010), and the Zafar in Karachi of Pakistan (Zafar et al., 2008). These results may be due to the similarity in drug consumption cultures in both societies.

According to the results of this study, no significant association was found among self-medication and demographic characteristics. Contrary to this finding, Purreza et al. study in Tehran University of Medical Sciences showed a significant relationship among demographic variables, including gender, family income, field of study, type of insurance and self-medication (Purreza et al., 2013). The results of the present study showed that no significant relationship existed between self-medication and the sex of the participant, as males and females were almost identical in the practice of self-medication. This result does not provide support for the findings of other studies that revealed that the sex variable plays an important role in self-medication (Lakey, Gray, \& Borson, 2009; Sawalha, Sweileh, Sa'ed, \& Jabi, 2008). This difference may be related to the number of samples in each group. In addition, in this study no significant association was found between the whether or not students considered their living costs as affordable and the prevalence of self-medication.

In summary, the results of this study, which is in line with other related studies, indicate that self-medication is a critical health issue. In the future, once they become doctors and medical professionals, students of medical science will be providing advice and information about medicine to the general public. For this reason, the relatively high prevalence of self-medication among medical science students, despite knowledge of its side effects, can induce widespread practice of self-medication among public.

\section{Conclusion}

Given the high prevalence of self-medication among medical students, it is necessary to raise awareness about this issue and improve students' attitudes and practices through the designing and implementation of preventive programs. These programs could include organizing awareness campaigns in the media, and teaching courses on the proper use of medicine and the consequences of self-medication. Also, it is important to identify and control the factors influencing students' behaviors. This study found excessive use of non-OTC medicines like dietary supplements, energizing medication, antibiotics, and gastrointestinal drugs, cold medications and painkillers, which can lead to serious side effects. It is necessary to control and supervise the sale of these drugs, and obtain a proper prescription from a physician.

Since the main source of drugs supply for practicing self-medication was the pharmacies and the drugs leftover 
from previous prescriptions, medication provided by pharmacies without a prescription should be limited. In addition to an increased monitoring of pharmacies to prevent the uncontrolled sale of OTC medicine, it may be helpful to implement a drug quota on individuals to prevent drug accumulation at home.

One of the limitations of this study includes recall bias of students in reporting the type of drugs that have been used for self-medication.

\section{Acknowledgements}

The authors would like to acknowledge all students participated in this study.

\section{Authors' Contribution}

All authors have participated in the study.

\section{Conflict of Interest}

The authors declare that there is no conflict of interests regarding the publication of this paper.

\section{References}

Albarrán, K. F., \& Zapata, L. V. (2008). Analysis and quantification of self-medication patterns of customers in community pharmacies in southern chile. Pharmacy world \& science, 30(6), 863-868. http://dx.doi.org/10.1007/s11096-008-9241-4

Alghanim, S. (2011). Self-medication practice among patients in a public health care system. East Mediterr Health J, 17(5), 409-425.

Almasdy, D., \& Sharrif, A. (2011). Self-medication practice with nonprescription medication among university students: A review of the literature. Archives of Pharmacy Practice, 2(3), 95-100 .

Amani, F., Mohammadi ,S., Shaker, A., \& Shahbazzadegan, S. (2011). Study of arbitrary drug use among students in universities of ardabil city in 2010. Journal of Ardabil University of Medical Sciences, 11(3), 201-207.

Ansari, H., Abshenas, M., Khanzadeh, G., \& Masoudi, G. (2007). Assessment of psychiatric drugs use and related factors among students of zahedan university of medical sciences. Fundamentals of Mental Health, 9(35-36), 145-152.

Baghianimoghadam, M., \& Ehrampoush, M. (2006). Evaluation of attitude and practice of students of yazd university of medical sciences to self-medication. Zahedan Journal of Research in Medical Sciences, 8(2), 111-119.

Barros, A. R. R., Griep, R. H., \& Rotenberg, L. (2009). Self-medication among nursing workers from public hospitals. Revista latino-americana de enfermagem, 17(6), 1015-1022. http://dx.doi.org/10.1590/S0104-11692009000600014

Brimstone, R., Thistlethwaite, J. E., \& Quirk, F. (2007). Behaviour of medical students in seeking mental and physical health care: Exploration and comparison with psychology students. Medical education, 41(1), 74-83. http://dx.doi.org/10.1111/j.1365-2929.2006.02649.x

Christie, J. D., Rosen, I. M., Bellini, L. M., Inglesby, T. V., Lindsay, J., Alper, A., \& Asch, D. A. (1998). Prescription drug use and self-prescription among resident physicians. JAMA, 280(14), 1253-1255.

da Silva, M. G. C., Soares, M. C. F., \& Muccillo-Baisch, A. L. (2012). Self-medication in university students from the city of rio grande, Brazil. BMC public health, 12(1), 339. http://dx.doi.org/10.1186/14712458-12-339

Eslami, A. A., Moazemi Goudarzi, A., Najimi, A., \& Sharifirad, G. R. (2012). Knowledge, attitude and practice of students in universities of isfahan, Iran toward self medication. Journal Health System Research 7(5), 541-549.

Ghafouri, M., Yaghubi, M., Lashkardoost, H., \& Seyed Sharifi, S. H. (2013). The prevalence of self medication among students of bojnurd universities and its related factors in 2013. Journal of North Khorasan University of Medical Sciences, 5(Student Research Committe Supplementary), 1129-1135.

Hem, E., Stokke, G., Tyssen, R., Grønvold, N. T., Vaglum, P., \& Ekeberg, Ø. (2005). Self-prescribing among young norwegian doctors: A nine-year follow-up study of a nationwide sample. BMC medicine, 3(16), 1 . http://dx.doi.org/10.1186/1741-7015-3-16

Hooper, C., Meakin, R., \& Jones, M. (2005). Where students go when they are ill: How medical students access 
health care. Medical education, 39(6), 588-593.

James, H., Handu, S. S., Al Khaja, K. A., Otoom ,S., \& Sequeira, R. P. (2006). Evaluation of the knowledge, attitude and practice of self-medication among first-year medical students. Medical principles and practice, 15(4), 270-275. http://dx.doi.org/10.1159/000092989.

Klemenc-Ketis, Z., Hladnik, Z., \& Kersnik, J. (2010). Self-medication among healthcare and non-healthcare students at university of ljubljana, slovenia. Medical Principles and practice, 19(5), 395-401. http://dx.doi.org/10.1159/000316380.

Lakey, S. L., Gray, S. L., \& Borson, S. (2009). Assessment of older adults' knowledge of and preferences for medication management tools and support systems. Annals of Pharmacotherapy, 43(6), 1011-1019. http://dx.doi.org/10.1345/aph.1L704.

Masoudi Alavi, N., Izadi, F., Ebadi, A., \& Hajbagheri, A. (2009). Self treatment experience in diabetes mellitus type 2. Iranian Journal of Endocrinology and Metabolism, 10(6), 581-588.

Montgomery, A., Bradley, C., Rochfort, A., \& Panagopoulou, E. (2011). A review of self-medication in physicians and medical students. Occupational medicine, 61(7), 490-497. http://dx.doi.org/10.1093/ occmed/kqr098.

Mumtaz, Y., Jahangeer, S. A., Mujtaba, T., Zafar, S., \& Adnan, S. (2011). Self medication among university students of karachi. J Liaquat Uni Med Health Sci, 10(3), 102-105.

Neafsey, P. J., Jarrín, O., Luciano, S., \& Coffman, M. J. (2007). Self-medication practices of spanish-speaking older adults in hartford, connecticut. Hispanic Health Care International, 5(4), 169-179. http://dx.doi.org/10.1891/154041507783095795.

Pfaffenbach, G., Tourinho, F. S., \& Bucaretchi, F. (2010). Self-medication among children and adolescents. Current drug safety, 5(4), 324-328. http://dx.doi.org/10.2174/157488610792246028.

Purreza, A., Khalafi, A., Ghiasi, A., Mojahed, F., \& Nurmohammadi, M. (2013). To identify self-medication practice among medical students of tehran university of medical science. Iranian Journal of Epidemiology, $8(4), 40-46$.

Roberts, L. W., Hardee, J. T., Franchini, G., Stidley, C. A., \& Siegler, M. (1996). Medical students as patients: A pilot study of their health care needs, practices, and concerns. Academic Medicine, 71(11), 1225-1232.

Sawalha, A. F. (2007). Assessment of self-medication practice among university students in palestine: Therapeutic and toxicity implications. The Islamic University Journal, 15(2), 67-82.

Sawalha, A. F., Sweileh, W. M., Sa'ed, H. Z., \& Jabi, S. W. (2008). Self-therapy practices among university students in palestine: Focus on herbal remedies. Complementary therapies in medicine, 16(6), 343-349.http://dx.doi.org/10.1016/j.ctim.2007.12.002.

Shadbolt, N. E. (2002). Attitudes to healthcare and self-care among junior medical officers: A preliminary report. The Medical Journal of Australia, 177, S19-20.

Shamsi, M., \& Bayati A. (2010). A Survey of the Prevalence of self-medication and the factors affecting it in pregnant mothers referring to health centers in arak city,2009. Pars Journal Of Medical Sciences (Jahrom Medical Journal), 7(3), 34-42.

Sharifirad, G., Mohebi, S., Motalebi, M., Abbasi, M., Rajati, F., \& Tal, A. (2012). The prevalence and effective modifiable factors of self medication based on the health belief model among elderly adult. Health System Research, 7(4), 1-10.

Siam, S. H. (2004). Assesment self-medication status in the city of rasht. Journal of Medical Sciences, Birjand, 10(1), 11-14.

Tabiei, S., Farajzadeh, Z., \& Eizadpanah, A. (2012). Self-medication with drug amongst university students of birjand. Modern Care Journal, 9(4), 371-378.

Verma, R.K., Mohan, L., \& Pandey, M. (2010). Evaluation of self medication among professional students in north india: Proper statutory drug control must be implemented. Asian Journal of Pharmaceutical and Clinical Research, 3(1), 60-64.

World Health Organization. (2002). Promoting rational use of medicines: Core components.

Yousefi, N., Majdzadeh, R., Valadkhani, M., Nedjat, S., \& Mohammadi, H. (2012). Reasons for physicians' tendency to irrational prescription of corticosteroids. Iranian Red Crescent Medical Journal, 14(11), 713-72. 
http://dx.doi.org/10.5812/ircmj.2284.

Zafar, S. N., Syed, R., Waqar, S., Zubairi, A. J., Vaqar, T., Shaikh, M., \& Saleem, S. (2008). Self-medication amongst university students of karachi: Prevalence, knowledge and attitudes. Journal of the Pakistan Medical Association, 58(4), 214-221.

\section{Copyrights}

Copyright for this article is retained by the author(s), with first publication rights granted to the journal.

This is an open-access article distributed under the terms and conditions of the Creative Commons Attribution license (http://creativecommons.org/licenses/by/3.0/). 